\title{
A Perspective on Training Methods Aimed at Building Local Capacity for the Assessment and Implementation of Environmental Flows in Rivers
}

\author{
Jeremy Howard O'Keeffe* \\ Environmental Learning Research Center, Rhodes University, Grahamstown, South Africa
}

This paper describes the development and delivery of a global training programme for environmental flows in rivers. The programme was developed in South Africa, and formalized with WWF. It has been delivered at various levels of detail, to specialist teams of scientists and managers (as learning-by-doing), and to large numbers of post-graduate students, in more than 20 countries worldwide. The intention has been to build local capacity and initiate $E$ flows implementation. The general format of the training is described, and a number of examples and case studies are used to demonstrate the successes and pitfalls of the process. The examples concentrate on the need for

OPEN ACCESS

Edited by:

Robert Alexander Speed, Badu Advisory Pty Ltd, Australia

Reviewed by:

Ben Stewart-Koster Griffith University, Australia Stuart E. Bunn,

Griffith University, Australia

${ }^{*}$ Correspondence: Jeremy Howard O'Keeffe j.okeeffe@ru.ac.za

Specialty section:

This article was submitted to

Freshwater Science,

a section of the journal

Frontiers in Environmental Science

Received: 09 May 2018 Accepted: 04 October 2018

Published: 23 October 2018

Citation:

O'Keeffe JH (2018) A Perspective on Training Methods Aimed at Building Local Capacity for the Assessment and Implementation of Environmental

Flows in Rivers.

Front. Environ. Sci. 6:125. doi: 10.3389/fenvs.2018.00125 long-term commitment and persistence in the face of multiple impediments, chief among them the need to change mind-sets of water policy makers, managers, scientists, and all levels of stakeholders, who traditionally view rivers as resources to be used to the maximum extent, rather than as valuable assets to be protected. They also illustrate examples of misunderstanding and resistance to implementing $E$ flows. Although there are many prerequisites for success in implementing $E$ flows, three essential ingredients for successful training and implementation have emerged over the past 25 years: the need for local champions, with a long-term commitment; the need for understanding and support from all levels of stakeholders; and the need (at least initially) to simplify the process as much as possible, so as to foster understanding and support, and to demonstrate successes within a time frame that maintains that support.

Keywords: river, environmental flows, training, capacity-building, implementation, lessons learned

\section{INTRODUCTION}

Environmental flows (E flows) "describe the quantity, timing, and quality of freshwater flows and levels necessary to sustain aquatic ecosystems, which in turn support human cultures, economies, sustainable livelihoods and well-being." (The Brisbane Declaration, 2007, in Arthington et al., 2018). This is one of the most important developments in water policy and management in the past 25 years, and even 8 years ago Le Quesne et al. (2010) stated that they knew of no major countries that do not now include, or are developing, legislation and policy that requires $\mathrm{E}$ flows. Arthington et al. (2018) confirm that many countries continue to introduce E flows into their water legislation.

This paper is a personal, and often anecdotal, recollection of the development and implementation of training courses, projects and programmes, mostly designed to kick-start 
environmental flows (E flows) implementation programmes in the host countries. Training programmes have been facilitated by the author in more than 20 countries around the world over the past 25 years. The training template (see below) gradually evolved as training-by-doing in more than 20 detailed environmental flow assessments (EFA) in South African rivers during the 1990's, and was formalized after a meeting of the WWF Global Water Programme in Hyderabad, India, in 2004. Subsequently, many of the trainings have been carried out as part of WWF river basin programmes, coordinated by local WWF country offices, and using local scientists and managers. This has the major advantages that the training is provided in response to a local demand, rather than following persuasion by a consultant, and the trainer is coming into the process as part of a local team, rather than as a foreign intruder. The training is designed to start a process, and to build local capacity, so that coherent decisions can be made, with sufficient experience and expertise, by national specialists and policy-makers, as to whether and how to implement $\mathrm{E}$ flows. As an outsider coming in, I have not felt it my place to proselytize or evangelize for $\mathrm{E}$ flows, and a viable exit strategy is required so that local interests take responsibility.

Since 2004, the trainings have varied from multiple-year programmes involving detailed EFAs on pilot rivers [the Rio Conchos in Mexico (WWF-Mexico, 2006), the Rio Sao Francisco in Brazil (Medeiros, 2008), the Mara River in Kenya/Tanzania (Lake Victoria Basin Committee and WWF-ESARPO, 2010)], the Great Ruaha River in Tanzania (WWF-Tanzania Country Office, 2010), the Kilombera sub-basin of the Rufiji River in Tanzania (McClain et al., 2016), the Upper Ganga River (O'Keeffe et al., 2012), and then the Ramganga River (Kaushal et al., 2018) in India), to shorter (one week to 1 year) projects in Wisconsin (USA), Ecuador, Peru, the UK, the Netherlands, Switzerland, Turkey, Mocambique, Zambia, South Africa, Pakistan, India, China, Mongolia, and Australia.

The ultimate objective of the training is to develop a team (or teams) of local scientists and managers, and informed stakeholders at all levels, who have experience with, and are eventually able to run their own E flows programme, so that the country can take ownership and responsibility for their own implementation. As will become clear, the results have been mixed, with the development of sustainable $\mathrm{E}$ flows programmes run by local teams in some countries (e.g., India), while in other countries (e.g., Mongolia) the initial training workshop has been followed by no observable follow-up or contact. This paper provides a description of the training model or template used, examines case studies of success and failure, and draws lessons which may help future training and capacity-building.

\section{THE TRAINING TEMPLATE}

The process developed with WWF was generally in response to the requirements of river basin initiatives run by WWF country offices. If such offices requested training in E flows, they would be asked to identify and contract a team of local scientists and managers, from local universities, research institutes, government ministries, and/or basin offices. The team should include: Hydrologist; Hydraulics surveyor/modeler; aquatic ecologists including at least fish and invertebrate specialists, and riparian/floodplain Botanist; Geomorphologist, preferably fluvial; Water Quality specialist; Sociologist and/or Socio/economist. A local coordinator (often from the WWF country office) should also be appointed, to oversee the organization and logistics of the training, and possibly to learn to facilitate the overall EFA process, with a view to becoming the local champion. The government/management agencies should be encouraged to appoint staff to attend and contribute to the entire training, with a view to taking ownership of the national process.

The process starts with the choice of a river or river section for a pilot EFA and training-by-doing. Ideally, this should be a relatively small river, not yet over-allocated. The size makes the field-work more manageable (and cheaper), and the limited allocation makes it easier to achieve an early implementation of E flows, demonstrating the success of the process. Unfortunately, these criteria are rarely met, because the lure of a large important river, already in crisis management, is too inviting. Such rivers offer high-profile opportunities, but are usually too complex and over-developed to offer quick success. Perhaps the best compromise is to choose a river of each sort, and embark on simultaneous pilot projects, providing both high profile and the prospect of a quick successful demonstration.

The facilitator would run an initial week-long training workshop, at which the preferred EFA methodology is decided upon, the tasks and responsibilities are defined for each specialist group, and a planning schedule is drawn up. This will usually be followed by a field trip with all the specialists, to choose sites suitable for hydraulic rating and detailed sampling; and to demonstrate and try-out sampling methods and data collection. Because the specialists are already expert in their own fields, the emphasis is simply on how to integrate their expertise within a clearly defined EFA process. Following the initial training, the local coordinator and team should be able to spend seasonal periods of the next year collecting and analyzing the required information. At different times in this process, meetings should be held with riparian and institutional stakeholders, to explain the purpose and process of the EFA, and to involve them in choosing environmental objectives for the pilot river. This is an extremely important part of the EFA process, since it can build understanding and ownership of the project, and an involvement in objective-setting lends legitimacy to the outcomes. An effective model for this stakeholder involvement is described in O'Keeffe et al. (2017) for the Rufiji River in Tanzania.

Once the field-work and analysis is complete, each specialist group should prepare a starter document, summarizing the available information and data collected, and providing a detailed set of flow-related objectives for their component. The document should also include classification tables for each site, indicating present state, current trajectory of change, the importance of improving or maintaining the component, and the proposed Ecological Management Class (EMC, the overall desired condition for each site). At the flow assessment workshop (usually a week long) the specialist groups discuss a range of seasonal flows for each site, and reach a consensus on which flows 
will provide for as many of the component objectives as possible. Each flow is then provided with detailed motivations, and a set of consequences if it is not provided. The hydrologist provides a check that the recommended flows are within the potential of the river to be provided (i.e., within the natural bounds of the flow regime). Normally, three different flow scenarios will be assessed-the target scenario which most closely achieves the environmental objectives, an improved scenario to reach a class higher than the target, and an increased use scenario which would reduce the environmental state by one class. These alternative scenarios provide managers with an idea of the consequences for water use of maintaining the river in different conditions. The flow assessment workshop will be run by the facilitator, while mentoring the proposed local champion.

Following the initial pilot project training, a second pilot EFA should be set up on another river. This pilot should be largely run by the local champion, as facilitator, with the outside facilitator as a background mentor and advisor. Ideally, the original specialist teams should carry out the second pilot, with changes dictated by their success in the initial EFA (see section on set-backs below). The original teams should include further apprentices to be trained in the process. After the second pilot EFA is completed, there should be at least one experienced specialist team in place, a local champion capable of facilitating the process, staff members of relevant government organizations who understand and can implement the recommended flows, and large numbers of stakeholders who have some understanding of the process.

\section{EXAMPLES}

\section{Implementation in Progress}

The training programmes are intended to provide an initial impetus for E flows implementation, by creating local capacity, understanding and momentum. Experience has shown that it will usually take a number of years, often more than a decade, before this impetus results in the provision of $\mathrm{E}$ flows in one or more rivers. An early example of this was the training in Mexico, where WWF-Mexico Country Office appointed a local team to assess E flows for the Rio Conchos in 2004. The Conchos is a large river, flowing northwards into the Rio Bravo/Grande, over-allocated for irrigation and with transboundary flow obligations to the USA. Typically for such a complex system, the implementation process has become bogged down, mainly by the intransigence of irrigation farmers, and latterly by the increasing lawlessness in the state of Chihuahua (Barrios, pers. comm., 23rd October, 2017). However, Eugenio Barrios (Director of Water Programmes, WWF-Mexico Country Office) goes on to write: "the Conchos E flow proposal was key to develop the Mexican E flow Standard, and later to change our approach to low water conflict basins. We created the water reserves concept to implement $\mathrm{E}$ flows. It has been very successful and currently we are on track to set $\mathrm{E}$ flows in 350 river basins out of 700" (Barrios, pers. comm., 23rd October, 2017). Barrios et al. (2015) lists 6 pilot basins in which flow implementation has already started.

A similar situation has developed in Brazil, where an initial E flows training was coordinated on the Lower Rio Sao Francisco, by Professor Yvonilde Medeiros of Bahia Federal University in 2006. Prof Medeiros is also a member and technical consultant on the Sao Francisco Water Basin Committee. The Sao Francisco is a large river and has a series of 5 hydro-power dams which feed into the national electricity grid. The EFA concentrated on the $50 \mathrm{~km}$ of river downstream of the lowest dam to the river mouth. The training EFA was completed in 2008, but implementation of the recommended $\mathrm{E}$ flows is still under discussion: "The National Water Authority (Agencia Nacional de Agua-ANA) are coordinating the member states of the Sao Francisco River Basin in a discussion about rules for reservoir operation during wet periods and periods of water scarcity" (Prof Medeiros, pers. comm., 23rd October, 2017).

India provides the most complete example of the training process. In 2009, an EFA was initiated by WWF-India on the Upper Ganga River, from Gangotri to Kanpur, combined with a training programme for a team of Indian scientists appointed by WWF-India. Although other E flows initiatives were also under way, the Ganga project was the first comprehensive assessment and training in India. The project was completed in 2012, and was followed by a second EFA on the Ramganga tributary of the Ganga. This second EFA was coordinated and facilitated by Nitin Kaushal, Associate Director-Sustainable Water Management \& Wild Rivers WWF-India, who was mentored by the author during the Ganga and Ramganga EFA's. Nitin was ably supported and encouraged by senior staff at WWF-India, including Suresh Babu (Director, River Basins and Water Policy) and Sejal Worah (Programme Director). Together, this team and some of the senior scientists on the E flows team approached the Government of the state of Uttar Pradesh, to release the recommended flows in the Ganga during the 6 weeks of the Kumbh Mela religious festival held at Allahabad from January to March, 2013. (Kumbh Mela is held once every 12 years, and attracts the largest gathering of people in the history of the world). The state government agreed to provide the flows, and the river was wide, deep, and relatively clean for the 89 million pilgrims who visited the river during the 6 weeks of the festival (WWF-India, 2013). Flow monitoring and interviews with pilgrims during the festival indicated that the recommended flows were met or exceeded throughout the 6 weeks, and that more than $95 \%$ of interviewees were satisfied with the state of the river during their visit (Kaushal, 2015; WWF-India, 2013). A further short-term "Demonstration E flow" is planned for the Ramganga (Kaushal, pers.comm., 23rd October, 2017), and these will hopefully demonstrate and promote the advantages of $\mathrm{E}$ flows to the Indian government and to local stakeholders. There is already a national policy advocating E flows, but, as Nitin points out: "National Water Policy 2012, and Ganga Notification of 2016 are key policy items, that talk about E Flows and are useful instruments. The Ganga River Basin Management Plan is a useful and powerful document to push for E Flows, but the state has to come on board which is a long-drawn game." (Kaushal, pers.comm., 23rd October, 2017).

Tanzania has been engaged in E flows research, assessment and training in a number of river basins since an early training course by the author in Dar es Salaam in 2005. The Water Resources Management Act of 2009 included the requirement 
for a Reserve, part 2 of which is for the protection of aquatic ecosystems, and is equivalent to an environmental flow. Training began with a joint Kenyan/Tanzanian project to assess E flows for the transboundary Mara River. This has been followed by EFA's on the Wami, Ruvu, Pangani, Great Ruaha and Kilombera Rivers (both the latter being sub-basins of the Rufiji River Basin). These projects have been facilitated by a number of different international consultants (including the author on the Mara, Ruvu, Great Ruaha, and Kilombera), using a variety of assessment methodologies, and all including elements of further training. A number of the same Tanzanian specialists have been used on many of the EFAs, so there is presently a local team of highly experienced specialists, familiar with a number of the commonly used EFA methodologies, on a range of different rivers (e.g., O'Keeffe, 2013). Despite the many assessments, implementation has been slow, at least partly due to the absence of a committed champion, either from the ranks of the specialists, or from government. According to Willie Mwaruvanda (a former Basin Officer for the Rufiji Basin, who was involved in the EFA for the Great Ruaha), E flows have been considered in the preparation of Integrated Water Resources Management and Development Plans in six Tanzanian river basins, but there has been so far "little implementation of E flows here in Tanzania. In the Ndembera [a tributary of the Great Ruaha] the design of a dam is complete. I think the Government is looking for funds for its construction. Its purpose will be to provide E flows for the Great Ruaha in the National Park" (Mwaruvanda, pers. comm., 31st October, 2017). The initial EFA for the Mara River was accepted by the Lake Victoria Basin South Commission (LVBSC), with plans to protect the E flows, which are almost entirely presently flowing down the river, as it has no large impoundments or major abstractions. Low flows during droughts are at risk of abstraction for irrigation, upstream of the Maasai Mara and Serengeti protected areas, so the LVBSC has put in place a requirement for on-farm, off-stream storage before any further irrigation licenses are approved. Similarly, the flows in the Kilombera Rivers are at present virtually natural and unabstracted, so that the E flows simply need to be kept in the rivers in the future, and there is plenty of potential for consumptive water uses above the E flow requirements.

The above case studies indicate at least some progress toward E flow implementation, and there are other cases where one can be hopeful that progress is being made. The shorter training courses in Wisconsin, the UK, the Netherlands, and Switzerland have all been attended by a majority of delegates from developing countries, usually as part of longer courses and post-graduate degrees in aspects of water management and science. Between 2005 and 2017, these courses have been presented to more than 430 present and future water professionals around the world (including at least one person who has since been appointed as his country's Minister of Water). It would be impossible to ascribe any E flows implementation solely to these courses, but one can surmise that delegates returning to their countries with an understanding of $\mathrm{E}$ flows will, at least in some cases, have helped to promote the process.

In other cases there has been significant implementation of $\mathrm{E}$ flows, but not as a result or even necessarily connected to the training that the author has facilitated. In China, for example, courses were provided to government staff, water managers and scientists on the Yellow River and the Yangtze, but the E flows in the Lower Yellow River pre-date the course (Gippel et al., 2012), and in the Yangtze were planned well before the course. Again, one can hope that the courses fed into a national groundswell of understanding and acceptance of E flows.

\section{Set-Backs, Impediments, and Lack of Noticeable Progress}

Important as the examples of progress are, it is just as useful to know that many projects to initiate E flows may founder and stall early on, and to understand why. My involvement in a number of countries (e.g., Peru and Mongolia) was over after an initial training workshop. This doesn't necessarily mean that no progress has been made through other channels. There are many possible reasons for the failure of $\mathrm{E}$ flow initiatives in different countries, despite the fact that most countries now include, or are developing, legislation and policy that requires E flows (Le Quesne et al., 2010). These may include a lack of capacity in one or more of the enabling factors listed here in the discussion (from Harwood et al., 2017), but, in my experience, the most common, and the most intractable factor is to change the mindset of people. O'Keeffe et al. (2017) suggest that "Introducing the idea of environmental flows to stakeholders (who may have little or no experience of the issue) is often challenging. Globally, there is a basic view that rivers are a very valuable resource for human use and that the main product they provide is freshwater, the basis of life, livelihoods, food production, industry, and sanitation. A consequence of this view is that water flowing out of the end of a river, if not a waste, may at least be perceived as a lost opportunity for improving human welfare. Accepting the premise of environmental flows, that water should be left in the river, and that a fairly high proportion of mean annual runoff may have to be left in the river if relatively good environmental conditions are to be maintained, requires a $180^{\circ}$ change of this mind-set. To convince people that this change is useful and desirable needs compelling reasons." Even when a country has the necessary legislation, which argues a national desire to implement $\mathrm{E}$ flows, the acceptance of the need to set aside significant amounts of (often scarce) water, rather than to use it to grow food etc., does not come easily, especially in countries where water ministries and management have traditionally been run by irrigation engineers and dam builders. It may take a generation before environmentally-minded managers come to the fore. In this paper, rather than list and analyse the many reasons that may get in the way of E flows implementation, I want to present examples which demonstrate some of the difficulties which people have in understanding and accepting E flows.

The following are examples where, for different reasons, elements of the E flows process has not worked, or been understood. The examples are not intended to ridicule the people involved, and names, rivers and (mostly) countries are left out to minimize personal offense. They rather illustrate the difficulties that many people, even experienced professionals and scientists, have in managing the concepts of E flows. The following are all cases which I personally experienced: 
Early on in the development of E flows, a very senior hydrologist commented, after an EFA presentation: "If you want to apply $20 \%$ of the mean annual runoff as an E flow, it is impossible to do that for a seasonal river, where there is zero flow in the dry season." In deference to his seniority and gray hairs, (I was young and timid then), I waited until afterwards to point out to him that $20 \%$ of zero is still zero, and that we were in no way advocating flows when the natural condition would be dry.

In the early days of the South African Water Act of 1998, a classification system of A to F was used, in which A class was pristine and natural, and $\mathrm{F}$ was critically/extremely modified. Classes $\mathrm{E}$ and $\mathrm{F}$ were designated environmentally unsustainable, and therefore unacceptable as management objectives. Any rivers currently in E or F class would, by default, need to be improved to at least D class (largely modified). It took very little time for a group of water professionals, resolutely anti-environmental flows, to propose that the management objectives for all rivers in A, B, or C classes should be to exploit them to a D class, since they would remain sustainable in this state. The purpose of $\mathrm{E}$ flows is certainly not to motivate for increased degradation of rivers.

In the course of discussions to set $\mathrm{E}$ flow requirements for a particular river, the fish specialist recommended seasonal flows extending into the riparian vegetation, at depths that would allow fish to forage for the invertebrates living among the reeds and rushes. The invertebrate specialist countered this with considerably shallower recommended flows, to prevent the fish from feeding on the invertebrates.

During one initial training course, we split the delegates into 5 groups to do separate assessments of E flows on the same floodplain section of a large river, which happened to form the state boundary between a northern and a southern state of the host country. Four of the groups came up with very similar quantities of environmental water, primarily to inundate the valuable floodplain forests. The fifth group recommended about half the water volume of the other groups. On enquiry, it became clear that all the members of the fifth group were from the southern state, and were certainly not going to allocate scarce water to the floodplains on the northern side, so had confined their recommendations to the southern banks of the river.

A very senior scientist, appointed to lead the biodiversity group at an initial training, was originally an algologist, and produced long species lists of his favorite family of algae for each EFA site, as his contribution to the E flows analysis, after two years of courses and field-work. I congratulated him on his endeavor, and asked him how he intended to use these lists to assess E flow requirements. "Flow?" he said, "I don't know anything about flow!”

A botanist appointed as riparian/floodplain vegetation specialist insisted that the vegetation needed to be permanently inundated, at least to its base. Since the river was deeply incised this would have required flows of around 50 times the natural flows during the dry season. He was adamant that this was nevertheless necessary.

A very senior scientist, appointed to lead his country's E flows programme, had a unique view of the EFA process, insisting that the only measurements relevant to setting E flows were water depths, and anything else was wasted effort. He was also adamant that flows have no effect on water quality.

A hydraulics engineer, appointed to provide rated crosssections of a large floodplain river, was obviously more used to working on in-stream structures such as weirs, and resolutely refused to extend his surveys beyond the immediate channelbanks of the river. As a result, the EFA was carried out without any quantifiable way of estimating floodplain water requirements.

These are only a few of the difficulties encountered in E flows work. Other examples include the many EFA methodologies designed to provide the minimum quantity of environmental water, among them the notorious Q95 $_{9}$ methodology (e.g., Lozano Sandoval et al., 2015), which sets E flows at constant extreme drought levels-a guarantee of eventual serious degradation to the ecosystem. In general, these impediments are of the following kinds:

- Those who are resolutely anti-environmental flows, considering them "a waste of water for fish and bugs" (e.g., 1, above). Thankfully, such environmental dinosaurs are increasingly rare.

- Those who reluctantly accept the requirement for some sort of E flows (usually where legislation requires it), but who exert every effort to ensure that only token water volumes are ever allocated (e.g., 2. above).

- Those specialists who become "component loyal" within the E flows process, insisting on flows purely for their species or processes, irrespective of hydrological possibilities or whole ecosystem effects (e.g., 3 and 6. above).

- Those who may be expert in their own field, but fail to make the transition to the multi-disciplinary requirements of $E$ flows (e.g., 4, 5, and 7. above).

Coping with such set-backs often requires strategies which could be described as low cunning, from the facilitation and coordination team. Many specialists are resistant to change, and seniority is often highly correlated with increasing resistance. Since holistic E flow processes rely on multi-disciplinary analysis and assessment, it is usually possible to leave out the more improbable flow recommendations, or hide them in unread appendices. For example, the algologist's biodiversity team included highly competent fish, mammal, reptile and invertebrate specialists whose combined analysis obviated the need to include input from the team leader. To be fair, the algologist provided baseline data which may well eventually prove valuable in understanding the biodiversity of the river, and the scientist in 6. Above is well-connected as an advisor to the national minister of water, and has been politically effective in promoting the concept of E flows, despite his eccentric grasp of the details.

\section{DISCUSSION}

This has been an unapologetically personal and largely subjective reflection of the E flows process. I accept that scientific credibility is a requirement for the implementation of $\mathrm{E}$ flows, but it is not in 
itself nearly sufficient, and this paper tries to trim the imbalance in much of the E flows literature, which concentrates on scientific understanding of the ecological effects of flow, and has developed increasingly complex processes for assessing and implementing E flows. Without the understanding and recognition of the purpose and importance of E flows, among policy makers, managers, scientists, and all other stakeholders, the most detailed scientific analysis will be impotent and unused. Scientific research underpins the prediction of the effects of flows on riverine ecosystems, but setting environmental objectives, deciding on management initiatives, promoting the implementation of $\mathrm{E}$ flows, and supporting the process, are all dependent on societal values, rather than science. I hope that I have shown that many people (even senior water professionals and scientists) struggle with the concepts and details of E flows, and are guided more by their biases and convictions than by any in-depth objective grasp of the technicalities. If even the specialists struggle with this, then how diverse and eccentric will the understanding of non-specialist stakeholders be? O'Keeffe et al. (2017) have argued for a simple stakeholder-enhanced approach to E flows, at least in the initial stages of implementation (and especially in developing ${ }^{1}$ countries), and other authors have shown the resistance and misunderstandings that can result from overelaboration (e.g., Dickens, 2011). A cogent argument is presented by Stirzaker et al. (2010) of the need to identify and stick to required levels of simplicity in dealing with complex problems, in which their hypothesis is that: "Decision makers responsible for natural resource management often complain that science delivers fragmented information that is not useful at the scale of implementation." I would argue for a graduated development of E flows capacity in countries new to the process, in which robust transparent methodologies, avoiding the use of opaque models, are initially used to familiarize local teams with the basics of $\mathrm{E}$ flows. Having gained a few years of experience and confidence, these teams can then choose to graduate to the more complex methodologies.

\section{Lessons Learned}

Harwood et al. (2017) list a series of "enabling factors" for the implementation of E flows, which they have culled from a review of a series of global case studies in the report. These are summarized as:

1. Legislation and regulation

2. Collaboration and stakeholder engagement and understanding

3. Driving force-a champion

4. Technical knowledge, understanding, and tools

5. Resources and capacity

6. Standards and guidelines

7. Monitoring networks and adaptive management

8. Reallocation and trading mechanisms

\footnotetext{
${ }^{1}$ I know that some people dislike the term developing countries, and consider it to be pejorative. I am profoundly proud to belong to a developing country, and would not want to be part of a so-called developed country, implying that nothing further needs to be understood or advanced. We all know of one or two powerful national leaders that embody this arrogant credo.
}

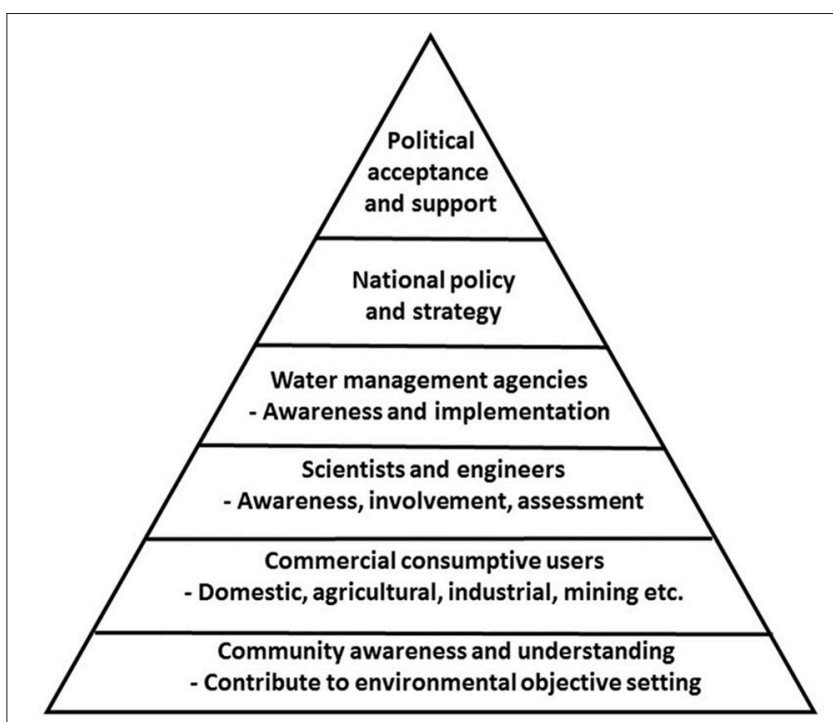

FIGURE 1 | Different levels of stakeholder involvement in the $E$ flows process. Modified from WWF-Zambia (2016).

I would agree that at least some application of all of these factors is required for successful E flow implementation, but, in my experience, the over-arching requirement is number 3the need for champions, with a long-term commitment to enabling and implementing the $\mathrm{E}$ flows process. Committed and effective champions can be the catalyst for initiating all the other enabling factors, but, without one (or more), the process at best becomes disoriented and dis-integrated. Eugenio Barrios (Mexico), Yvonilde Medeiros (Brazil) and Nitin Kaushal and his colleagues (India), are all examples of champions who have been engaged for more than a decade, and continue to build support and capacity for $\mathrm{E}$ flows in their countries. Ideally, two champions, or even a group, should be the aim. One should be from the government agency tasked with E flow implementation, and the other(s) may be from a university, research institute, an NGO such as WWF, and/or from a major stakeholder group. It has also become clear that factor 2stakeholder engagement and understanding, is a pre-requisite for success, as I have argued above. Figure 1 provides a "stakeholder pyramid," indicating the different levels of involvement in the $\mathrm{E}$ flows process.

I would add two more lessons that can facilitate the E flows process and help to ensure fairly rapid implementation. They are both simplifications of the process that are not always possible, but should be sought out, because they can fast-track success and provide demonstrations of the advantages of the process:

1. Find a river (such as the Kilombero or Mara, discussed above) which is currently relatively unstressed and not over-allocated, so that the E flows are still in the river, and don't have to be clawed back from unenthusiastic users.

2. Start the process on a small river which is accessible, easy to work on, and in which $\mathrm{E}$ flows are more likely to be implemented. 
Initial successful demonstrations, achieved relatively quickly (in a matter of years rather than decades), are infinitely more persuasive than any number of theoretical discussions, meetings and workshops. The resistance to these simplifications, as I have pointed out in the case studies, is that such rivers may not have the high profile, priority and importance of large complex rivers such as the Ganga, Sao Francisco or Conchos. The case of the Mara is fortunate because it is not only relatively unallocated at present, but it drives the iconic mass migrations of millions of wild animals in the Maasai Mara and Serengeti, which earn large amounts of foreign exchange in tourism for Kenya and Tanzania, so that it has the high profile and importance as well.

This paper is about the people involved in E flows assessment and implementation-how they can help the process and how they can hinder it. There is ample literature about the scientific aspects of $\mathrm{E}$ flows, but this paper takes the science as an accepted requirement, and makes the point that the people involved, their knowledge, beliefs, and biases, their commitment and persistence, are probably more important in determining the success or failure of $\mathrm{E}$ flows than any other factor.

\section{REFERENCES}

Arthington, A.H., Bhaduri, A., Bunn, S.E., Jackson, S.E., Tharme, R.E., Tickner, D., et al. (2018). The Brisbane Declaration and global action agenda on environmental flows 2018. Front. Environ. Scie. 6:45. doi: 10.3389/fenvs.2018.00045

Barrios, E., Salinas Rodríguez, S., Martínez, A., López Pérez, M., Villón Bracamonte, N., and Ángeles, F. (2015). National Water Reserves Program in Mexico. Experiences with Environmental Flows and the Allocation of Water for the Environment. Inter-American Development Bank Technical Note 864.

Dickens, C. (2011). Critical Analysis of Environmental Flow Assessments of Selected Rivers in Tanzania and Kenya. Nairobi: IUCN ESARO office and Scottsville, South Africa.

Gippel, C.J., Jiang, X., Cooling, M., Kerr, G., Close, P., Jin, S., et al. (2012). Environmental Flows Assessment for the Lower Yellow River. Brisbane, QLD: International WaterCenter.

Harwood, A., Johnson, S., Richter, B., Locke, A., Yu, X., and Tickner, D. (2017). Listen to the River: Lessons From a Global Review of Environmental Flow Success Stories. WWF-UK, Woking.

Kaushal, N. (2015). Ganga River Environmental Flows initiative for Triveni Sangam. Allahabad. Unpublished report of WWF-India.

Kaushal, N., Babu, S., Mishra, A., and O'Keeffe, J. (2018). Environmental Flows for a Healthy Ramganga. Report of WWF-India, Rivers for Life Programme.

Lake Victoria Basin Committee and WWF-ESARPO (2010). Assessing Reserve Flows for the Mara River. Nairobi; Kisumu.

Le Quesne, T., Kendy, E., and Weston, D. (2010). The Implementation Challenge: Taking Stock of Government Policies to Protect and Restore Environmental Flows. Report of WWF and The Nature Conservancy. WWF-UK, Godalming; Surrey.

Lozano Sandoval, G. L., Durango, E. A. M., Reinoso, P. L. G., Mejía, C. A. R., Juan Pablo Gómez Ospina, J. P. G. and Loaiza, H. T. L. (2015). Environmental Flow Estimation Using Hydrological and Hydraulic Methods for the Quindio River Basin: WEAP as a support tool. Vol 11. Inge CUC, 34-48.

McClain, M., Tharme, R., O’Keeffe, J., Kasanga, W., Corzo, G., Crosato, A., et al. (2016). Environmental Flows in the Rufiji River Basin Assessed From the Perspective of Planned Developments in the Kilombera and Lower Rufiji Sub-Basins. Report published by USAID.

\section{AUTHOR CONTRIBUTIONS}

The author confirms being the sole contributor of this work and has approved it for publication.

\section{FUNDING}

The work and projects described in this paper have been funded by a large number of research agencies, NGO's, universities, government departments, and aid agencies from many different countries. The preparation and writing of the manuscript were undertaken by the author without any external funding.

\section{ACKNOWLEDGMENTS}

I would like to pay special thanks to the many WWF country offices around the world, who have provided me with the opportunities, looked after me during my visits, coordinated and organized the training programmes, and often provided the funding, over the past 13 years. I am also grateful to Sue Southwood for her review, comments and corrections.

Medeiros, Y. (2008). Integrated Water Resources Management in Large Rivers. São Francisco River Experience. Unpublished presentation, Federal University of Bahia, Brazil.

O'Keeffe, J. (2013). Framework and Guidelines for the Assessment and Monitoring of Environmental Flows in Tanzania. Unpublished report to the Tanzanian Ministry of Water.

O'Keeffe, J., Graas, S., Mombo, F., and McClain, M. (2017). Stakeholder-Enhanced Environmental Flow Assessment: The Rufiji Basin Case Study in Tanzania. River Research \& Applications.

O'Keeffe, J. H., Kaushal, N., Smakhtin, V., and Bharati, L. (2012). Assessment of Environmental Flows for the Upper Ganga Basin. Report for WWF India.

Stirzaker, R., Biggs, H., Roux, D., and Cilliers, P. (2010). Requisite simplicities to help negotiate complex problems. Ambio 39, 600-607. doi: 10.1007/s13280-010-0075-7

The Brisbane Declaration (2007). Available online at: http://riverfoundation.org. au/wp- content/uploads/2017/02/THE-BRISBANE-DECLARATION.pdf

WWF-India (2013). Report on Environmental Flows for Kumbh 2013. Report by WWF-India.

WWF-Mexico (2006). Documento de Preparacion de la Informacion Para el Taller de Gasto Ecologico. Fichas Técnicas. ITESM Campus Monterrey.

WWF-Tanzania Country Office (2010). Assessing Environmental Flows for the Great Ruaha River, and Usangu Wetland, 274.

WWF-Zambia (2016). Proceedings of the E flows Technical Resource Group Introductory Workshop. Hosted by Water Resources Management Authority with support from WWF.

Conflict of Interest Statement: The author declares that the research was conducted in the absence of any commercial or financial relationships that could be construed as a potential conflict of interest.

Copyright (C) 2018 O'Keeffe. This is an open-access article distributed under the terms of the Creative Commons Attribution License (CC BY). The use, distribution or reproduction in other forums is permitted, provided the original author(s) and the copyright owner(s) are credited and that the original publication in this journal is cited, in accordance with accepted academic practice. No use, distribution or reproduction is permitted which does not comply with these terms. 